\title{
Development of a Photoswitchable Lithium-Sensitive Probe to Analyze Nonselective Cation Channel Activity in Migrating Cancer Cells $\mathbf{s}$
}

\author{
Jinxin V. Pei, Sabrina Heng, Michael L. De leso, Georgina Sylvia, Mohamad Kourghi, \\ Saeed Nourmohammadi, Andrew D. Abell, and (1)Andrea J. Yool
}

Adelaide Medical School, and the Institute for Photonics and Advanced Sensing (IPAS) (J.V.P., M.D.I., M.K., S.N., A.J.Y.) and ARC Centre of Excellence for Nanoscale BioPhotonics, IPAS, School of Physical Sciences (S.H., G.S., A.D.A.), University of Adelaide, Adelaide, South Australia, Australia

Received December 3, 2018; accepted March 5, 2019

\section{ABSTRACT}

This is the first work to use a newly designed $\mathrm{Li}^{+}$-selective photoswitchable probe Sabrina Heng Lithium (SHL) in living colon cancer cells to noninvasively monitor cation channel activity in real time by the appearance of lithium hot spots detected by confocal microscopy. Punctate $\mathrm{Li}^{+}$hot spots are clustered in the lamellipodial leading edges of HT29 human colon cancer cells and are colocalized with aquaporin-1 (AQP1) channels. AQP1 is a dual water and cyclic-nucleotidegated cation channel located in lamellipodia and is essential for rapid cell migration in a subset of aggressive cancers. Both the $\mathrm{Li}^{+}$hot spots and cell migration are blocked in HT29 cells by the AQP1 ion channel antagonist AqB011. In contrast, $\mathrm{Li}^{+}$hot spots are not evident in a poorly migrating colon cancer cell line, SW620, which lacks comparable membrane expression of
AQP1. Knockdown of AQP1 by RNA interference in HT29 cells significantly impairs $\mathrm{Li}^{+}$hot spot activity. The SHL probe loaded in living cells shows signature chemical properties of ionic selectivity and reversibility. Dynamic properties of the $\mathrm{Li}^{+}$hot spots, turning on and off, are confirmed by time-lapse imaging. $\mathrm{SHL}$ is a powerful tool for evaluating cation channel function in living cells in real time, with particular promise for studies of motile cells or interlinked networks not easily analyzed by electrophysiological methods. The ability to reset SHL by photoswitching allows monitoring of dynamic signals over time. Future applications of the $\mathrm{Li}^{+}$probe could include high-throughput optical screening for discovering new classes of channels, or finding new pharmacological modulators for nonselective cation channels.

\section{Introduction}

Cell migration is central to critical processes of repair, regeneration, immune protection, development, and maintenance of multicellular organisms, and in disease conditions such as cancer metastasis (Friedl and Wolf, 2003; Papadopoulos et al., 2008; Olson and Sahai, 2009; Petrie et al., 2009; Krummel et al., 2016). In addition to regulating fluid balance (Agre et al., 1993; King et al., 2004), some aquaporins facilitate rapid cell migration. For example, aquaporin-1 (AQP1) enhances the mobility of some of the most motile cells, such as T cells,

This work was supported by the Australian Research Council [Grants DP160104641 and DP190101745]. Sensor development was supported by the Centre for Nanoscale BioPhotonics, with funding from the Australian Research Council [Grant CE140100003].

Part of this work was presented at the 2018 Biophysics Conference, and the abstract was published in the following Biophysical Journal conference proceedings: Pei JV, Heng S, De Ieso M, Sylvia G, Kourghi M, Abell AD, and Yool AJ (2018) Real-Time Imaging of Lithium 'Hot-Spots': An Analysis of Ion Conductance in Aquaporin-1 using Novel Photo-Switchable Sensor Biophys J 114:360a DOI: 10.1016/j.bpj.2017.11.1999.

https://doi.org/10.1124/mol.118.115428.

S This article has supplemental material available at molpharm. aspetjournals.org. fibroblasts, cancers, and amoebae (Pei et al., 2016a). While the exact mechanisms have yet to be determined, we do know that elevated expression of AQP1 is apparent at the leading edges of lamellipodia in these classes of migrating cells. Genetic knockdown of AQP1 expression can impair cell migration significantly (Hu and Verkman, 2006; McCoy and Sontheimer, 2007), whereas reintroduction of AQP1 but not other channels, such as AQP4, can restore motility (McCoy and Sontheimer, 2007). A major difference is that AQP1, but not AQP4, can function as a nonselective monovalent cation channel gated by cGMP, as well as a water channel (Anthony et al., 2000; Boassa and Yool, 2003). Dissecting the role of AQP1 ion channels in cell migration would advance our knowledge of basic mechanisms that enhance motility in cancer, stem cells, and regenerating tissues, and identify possible targets for intervention, such as in cancer metastasis.

Here, we demonstrate that a newly designed reversible lithium sensor Sabrina Heng Lithium (SHL) can be used to monitor cation channel activity in living cells, and we demonstrate proof of principle using a metastatic colon cancer cell line (HT29) that relies on high levels of AQP1 expression for rapid migration capability (Dorward et al., 2016) as compared with a

ABBREVIATIONS: AQP1, aquaporin-1; DMEM, Dulbecco's modified Eagle's medium; Em, emission; Ex, excitation; MC, merocyanine; PBS, phosphate-buffered saline; PCR, polymerase chain reaction; RFU, relative fluorescence unit; RT, room temperature; SHL, Sabrina Heng Lithium; siRNA, small interfering RNA; SP, spiropyran; TEA, tetraethylammonium. 
relatively sedentary colon cancer line (SW620), which lacks high AQP1 expression (Smith et al., 2018). SHL was designed to be selective for a low-abundance monovalent ion, $\mathrm{Li}^{+}$, over $\mathrm{Na}^{+}$and $\mathrm{K}^{+}$. AQP1 ion channels have properties that make them an excellent choice for this study; once activated, they show long open times (with open bursts lasting hundreds of milliseconds), a high single-channel conductance (150 pS in physiologic salines), and high permeability to monovalent cations $\mathrm{Na}^{+}, \mathrm{K}^{+}$, and $\mathrm{Cs}^{+}$(Anthony et al., 2000). Work here shows the AQP1 ion channel is also permeable to $\mathrm{Li}^{+}$and, thus, can be hypothesized to enable $\mathrm{Li}^{+}$ion influx, which could be detected by the SHL probe. The exciting finding that launched this study was the observation that the punctate SHL signals are clustered in the lamellipodia of migrating cancer cells. Subsequent confirmation that SHL detects AQP1-mediated $\mathrm{Li}^{+}$entry took advantage of the selective AQP1 ion channel inhibitor (AqB011), cation-substituted extracellular salines, and molecular knockdown of AQP1 to show that $\mathrm{Li}^{+}$entry into the cells and the punctate hot spot signals depended on the presence of ion-conducting AQP1 channels.

Results here show that activation of the sensor intracellularly is dependent on transport of extracellular $\mathrm{Li}^{+}$into the cell. Since the SHL probe is membrane-permeable, it is expected to be uniformly distributed through the cell; the presence of discrete points of fluorescent signal ("hot spots") implies locations of increased lithium entry. Selective inhibition of AQP1 with AqB011 and knockdown of AQP1 with small interfering RNA show that the $\mathrm{Li}^{+}$transport occurs through AQP1 channels. These results provide the first evidence of hot spots that colocalize with nonselective monovalent cation channels, as confirmed by properties of pharmacological sensitivity, ion selectivity, and levels of expression. These data illustrate the selectivity and applicability of the SHL probe as a powerful biologic tool and add further support to the idea that the ion channel function of AQP1 is an intriguing target for new strategies to manage AQP1-expressing cancers.

\section{Materials and Methods}

Oocyte Expression and Electrophysiology. Two electrode voltage clamp recordings were used to determine the ability of $\mathrm{Li}^{+}$to carry current in AQP1-expressing oocytes. Oocyte preparation and cRNA injection were performed as detailed in previous studies (Kourghi et al., 2016; Pei et al., 2016b). In brief, with a protocol approved by the University of Adelaide Animal Ethics Committee (M2018-016) in accord with Australian National Guidelines, partial ovariectomy of anesthetized adult Xenopus laevis female frogs was used to obtain lobes of unfertilized oocytes. Oocytes were separated from follicular coats with collagenase, rinsed in $\mathrm{Ca}^{2+}$-free isotonic $\mathrm{Na}^{+}$saline, and incubated in frog Ringer's saline at $16-18^{\circ} \mathrm{C}$. Selected oocytes were injected with $30-50 \mathrm{nl}$ of sterile water with and without $1 \mathrm{ng}$ of cRNA from cloned human Aquaporin-1 (NM_198098), linearized, and transcribed in vitro as per published methods. Oocytes without AQP1 cRNA served as nonAQP-expressing controls. Recordings were performed at room temperature in standard isotonic $\mathrm{Na}^{+}$saline or in $\mathrm{Li}^{+}$-substituted isotonic saline containing either $100 \mathrm{mM} \mathrm{NaCl}$ or $100 \mathrm{mM} \mathrm{LiCl}$, and $2 \mathrm{mM}$ $\mathrm{KCl}, 4.5 \mathrm{mM} \mathrm{MgCl}_{2}$, and $5 \mathrm{mM}$ HEPES, $\mathrm{pH}$ 7.3. Capillary glass electrodes (1-3 M $\Omega ; 1 \mathrm{M} \mathrm{KCl)} \mathrm{were} \mathrm{used} \mathrm{for} \mathrm{recordings.} \mathrm{cGMP} \mathrm{was}$ applied to the bath saline at a final concentration of $10-20 \mu \mathrm{M}$ using the membrane-permeable cGMP analog [Rp]-8-[para-chlorophenylthio]-cGMP (Sigma-Aldrich, Castle Hill, NSW, Australia). Ion conductances were determined by linear fits of current amplitudes as a function of voltage, applied by a step protocol from +60 to $-110 \mathrm{mV}$ from a $-40-\mathrm{mV}$ holding potential (Kourghi et al., 2016; Pei et al., 2016b). Ionic conductance values were monitored over 25 minutes after the bath application of cGMP to allow sufficient time to achieve maximal response. Recordings were done using a GeneClamp amplifier and pClamp 9.0 software (Molecular Devices, Sunnyvale, CA).

Cancer Cell Cultures and Confocal Imaging. HT29 and SW620 colorectal cancer cell lines (American Type Culture Collection, Manassas, VA) were cultured in Dulbecco's modified Eagle's medium (DMEM) supplemented with $10 \%$ fetal bovine serum $(\mathrm{v} / \mathrm{v})$, penicillin and streptomycin (100 U/ml each), and $1 \times$ glutaMAX (Life Technologies, Scoresby, VIC, Australia), referred to as complete DMEM. Cultures were maintained in $5 \% \mathrm{CO}_{2}$ at $37^{\circ} \mathrm{C}$. Cells were seeded on eight-well uncoated Ibidi $\mu$-Slides (Ibidi, Munich, Germany) at a density of $1.0 \times 10^{5}$ cells $/ \mathrm{ml}$ and allowed 24 hours to settle.

All imaging experiments were performed in a darkroom. Prior to imaging, cells were incubated with $50 \mu \mathrm{M}$ SHL sensor for 2 hours, then washed twice with warm phosphate-buffered saline. For the AqB011treated group, cells were then incubated with 20 to $80 \mu \mathrm{M} \mathrm{AqB011}$ for 2 hours or with vehicle ( $0.1 \%$ dimethylsulfoxide). All cells were stained with $0.5 \mathrm{mg} / \mathrm{ml}$ of Hoechst 33258 for 20 minutes. Either $\mathrm{Li}^{+}$saline $\left(137 \mathrm{mM} \mathrm{LiCl}, 3.5 \mathrm{mM} \mathrm{KCl}, 0.68 \mathrm{mM} \mathrm{KH}_{2} \mathrm{PO}_{4}, 5 \mathrm{mM}\right.$ HEPES, $10 \mathrm{mM}$ glucose, and $4.4 \mathrm{mM} \mathrm{MgSO}_{4}$ ) or tetraethylammonium ( $\mathrm{TEA}^{+}$) saline (with $137 \mathrm{mM}$ TEA Cl substituted for $\mathrm{LiCl}$ and all other components identical to those in $\mathrm{Li}^{+}$saline) was used for the imaging. The $\mu$-Slide was mounted on a Leica TCS SP5 laser-scanning confocal microscope (Leica, Wetzlar, Germany) with the $63 \times$ objective selected. To detect the signal emitted by the SHL sensor, the following excitation $(\mathrm{Ex}) / \mathrm{emission}(\mathrm{Em})$ setting was used: $\mathrm{Ex}=513 \mathrm{nM} / \mathrm{Em}=550 \mathrm{~nm}-700 \mathrm{nM}$. For visualizing Hoechst 33258 staining, the following setting was used: $\mathrm{Ex}=405 \mathrm{nM} / \mathrm{Em}=425-500 \mathrm{nM}$.

Small Interfering RNA Transfection. HT29 cells were cultured in six-well plates or eight-well uncoated Ibidi $\mu$-Slides in complete DMEM medium to reach $30 \%$ confluency prior to transfection. Transfection with Lipofectamine 2000 (11668019; Life Technologies) used $50 \mathrm{nM}$ of either Ambion Silencer Select AQP1 siRNA (4390824; Life Technologies) or Ambion Silencer Select Negative Control \#1 siRNA (4390843; Life Technologies), together with $50 \mathrm{nM}$ Dharmacon siGLO Green Transfection Indicator (D-001630-01-05; Millennium Science, Mulgrave, VIC, Australia). Cells were incubated in $5 \% \mathrm{CO}_{2}$ at $37^{\circ} \mathrm{C}$ for 48 hours prior to confocal imaging or real-time polymerase chain reaction (PCR) analyses. For signals emitted by siGLO Green, the setting $\mathrm{Ex}=496 \mathrm{nM} / \mathrm{Em}=506 \mathrm{~nm}-606 \mathrm{nM}$ was used

Quantitative Reverse-Transcription Polymerase Chain Reaction. At 48 hours post-transfection, cells were harvested from six-well plates, and RNA was extracted using Invitrogen PureLink RNA Mini Kit (1876897; Life Technologies) according to the manufacturer's protocol. RNA was quantified in Take3 Micro-Volume Plates with a Synergy 2 plate reader (BioTek, Winooski, VT). RNA (1 $\mu \mathrm{g})$ was reverse transcribed using the QuantiNOVA Reverse Transcription kit (205413; Qiagen, Chadstone Centre, VIC, Australia). Quantitative reverse-transcription polymerase chain reactions of the reference sequence ribosomal protein S13 (RPS13) and AQP1 were performed using SYBR Select Master Mix (4472908; Life Technologies) in triplicate using the Rotorgene 6000 (Qiagen). Primers used for AQP1 were as follows: forward primer, AGTCACTTCCCCAAGATCTGC; reverse primer, CAGGTGGGTCCCTTTCTTTCA.

Immunohistochemistry. Cells were cultured in eight-well Ibidi $\mu$-Slides to achieve $50 \%$ confluency prior to the experiment. Cells were rinsed with phosphate-buffered saline (PBS), fixed in $4 \%$ paraformaldehyde for 20 minutes at room temperature (RT), and washed four times in PBS (5-minute washes at RT) on a rocker. Cells were permeabilized with $0.1 \%$ PBS Tween for 5 minutes, washed three times with PBS at RT for 5 minutes on a rocker, and then blocked with $10 \%$ goat serum in PBS (GS/PBS) for 40 minutes at RT on a rocker. Incubation with the rabbit anti-AQP1 antibody (ab15080; Abcam, VIC, Australia) in $0.1 \%$ GS/PBS lasted 2 hours at RT. The cells were then washed three times in PBS ( 7 minutes; RT) on a rocker and incubated with AlexaFluor 488-conjugated goat anti-rabbit antibody 
(ab150077; Abcam) diluted in 0.1\% GS/PBS (35 minutes; RT, in the dark). After washing three times in PBS (7 minutes; RT) on a rocker, cells were incubated with Hoechst 33258 (Sigma-Aldrich) for 5 minutes in the dark. The cells were rinsed with PBS twice and mounted using Hydromount mounting medium (Sigma-Aldrich).

In Cell Photoswitching Experiment. The plate was mounted on a microscope with an overhanging UV lamp and table light. The first image was taken after the plate had been exposed to white light for 10 minutes (OFF1). The second image was taken after subsequent UV (632 nM) light exposure for 10 minutes (ON1). Over the next 10 minutes, images were captured every 2 minutes during white light exposure, ending with the seventh image (OFF2). The final image was taken after 10-minute incubation in total darkness (ON2). Fluorescent intensities were quantified using ImageJ software (National Institutes of Health, Bethesda, MD).

Chemical Synthesis and Characterization. Details for the synthesis of SHL are reported as Supplemental Materials (Supplemental Synthesis Experiment and Supplemental Scheme 1). The characterization of SHL is provided as Supplemental Materials (Supplemental Spectroscopic Experiments), which show the absorbance spectrum (Supplemental Fig. 1), Job's plot analysis of binding stoichiometry (Supplemental Fig. 2), photoswitching properties (Supplemental Fig. 3), metal ion titration tests (Supplemental Fig. 4), and results for excitation to emission to absorbance integration (Supplemental Fig. 5).

Statistics. Differences were analyzed for significance using one-way analysis of variance for multiple comparisons where relevant and post hoc analyses by Student's unpaired $t$ test unless otherwise indicated.
Results are reported as $P<0.001$ (***) and $P<0.0001$ (****); $n$ values are indicated above the $x$-axis $(n)$ in histograms.

\section{Results}

Design and Characterization of the Reversible Lithium Sensor SHL. The sensor described here (see Fig. 1A for SHL structure) contains a photochromic spiropyran that can be reversibly switched between a nonfluorescent spiropyran isomer (SP) and a charge-delocalized fluorescent merocyanine isomer (MC) when interacting with an appropriate metal ion (Rivera-Fuentes et al., 2015), such as $\mathrm{Li}^{+}$(Fig. 1A). The ability to switch between the two states is advantageous for visualizing $\mathrm{Li}^{+}$transport into cells. SHL shows enhanced fluorescence when complexed to $\mathrm{Li}^{+}\left(\mathrm{MC}^{+} \mathrm{Li}^{+}\right.$complex in Fig. 1A) while maintaining low background fluorescence in the absence of the ion (SP isomer in Fig. 1A). This sensor characteristic is desirable for visualizing ion binding with confocal microscopy and is predicted to yield better resolution than conventional fluorescent probes due to its enhanced signal-to-background ratio (Kolmakov et al., 2010; Klajn, 2014). A critical characteristic of the SHL sensor is its selectivity for $\mathrm{Li}^{+}$over other biologically abundant ions. We showed that incorporation of suitable ionophores on the spiropyran nucleus provided selective binding of defined ions (Heng et al., 2017). Here, we incorporated a 1-aza-15-crown-5 substituent at

A<smiles>CN1c2ccccc2C(C)(C)C12C=Cc1cc([N+](=O)[O-])cc(CN3CCOCCOCCOCCOCC3)c1O2</smiles>
Ring-closed SP isomer
low fluorescence

B

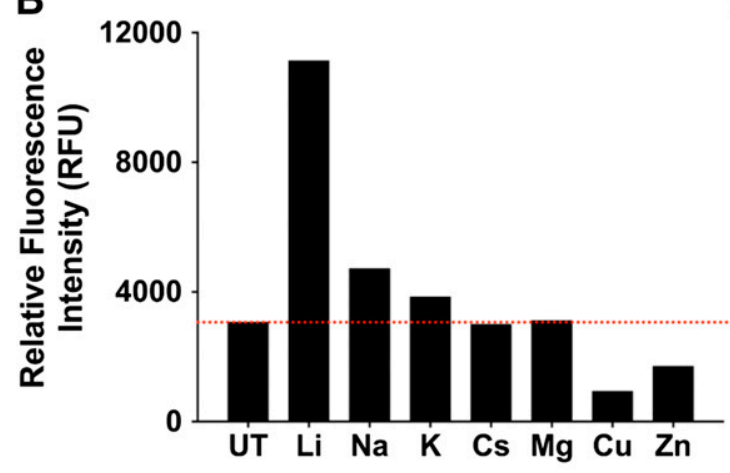

C
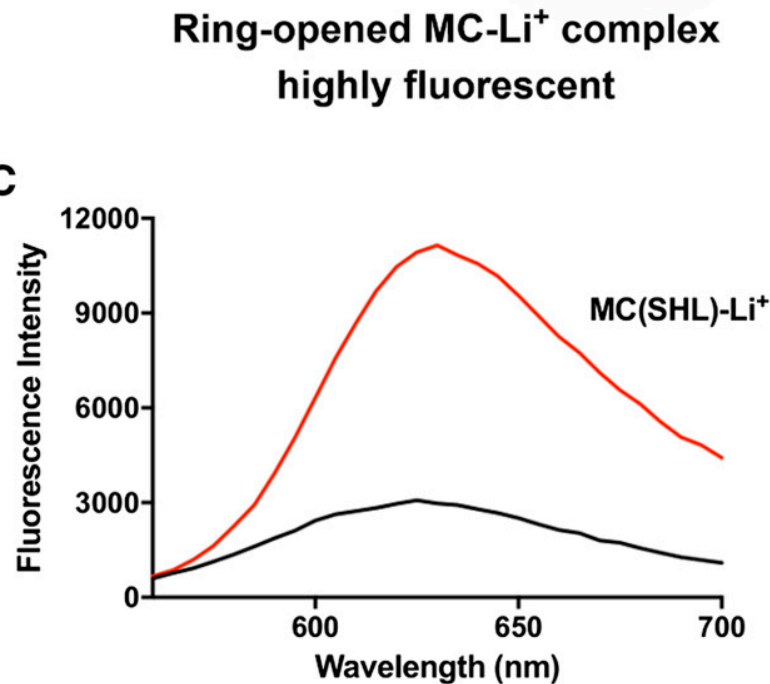

Fig. 1. Properties of the lithium sensor SHL. (A) Structures of the SP and merocyanine-lithium complexes of the sensor SHL [MC(SHL)-Li $\left.{ }^{+}\right]$and reversible binding of $\mathrm{Li}^{+}$. The ring-closed spiropyran has lower fluorescence than the open merocyanine. (B) Fluorescence intensities of SHL (50 $\left.\mu \mathrm{M}\right)$ in the presence of $\mathrm{Li}^{+}$or other biologically relevant metal ions. Excitation wavelength $=532 \mathrm{~nm}$; emission wavelength $=625 \mathrm{~nm}$. $(\mathrm{C})$ Fluorescence spectra of SHL in water $(50 \mu \mathrm{M})$. Black spectrum, SHL with no added $\mathrm{Li}^{+}$; red spectrum, SHL with $\mathrm{Li}^{+}(100 \mu \mathrm{M})$. 
C8 and a hydroxyethyl substituent at $\mathrm{N} 1$ to impart selectivity for $\mathrm{Li}^{+}$(Fig. 1A). Finally, we incorporated an $\mathrm{NO}_{2}$ substituent at $\mathrm{C} 6$ of the benzopyran ring as an electron-withdrawing group at that position, known to stabilize the ring-opened MC form, thus favoring ion binding. Details on the synthesis of SHL are reported in the synthesis section of the Supplemental Information. In brief, the $\mathrm{Li}^{+}$sensor was prepared from 1-aza15-crown-5 and 1-(2-hydroxyethyl)-2,3,3-trimethyl-3H-indol-1ium to give SHL with an overall yield of $20 \%$ using a modification to existing methodology (Heng et al., 2013; Stubing et al., 2016).

The addition of excess $\mathrm{Li}^{+}(100 \mu \mathrm{M})$ to SHL $(50 \mu \mathrm{M})$ gave rise to strong fluorescence $\left(\lambda_{\text {ex }}=532 \mathrm{~nm}\right)$ at approximately $\lambda_{\mathrm{em}}=635 \mathrm{~nm}$, as shown in Fig. 1C, which is consistent with the formation of the $\mathrm{MC}(\mathrm{SHL})-\mathrm{Li}^{+}$complex as expected based on our sensor design. Importantly, the red fluorescence represents an emission bandwidth that is distinct from the blue nuclear stain (Hoechst 33258) and green AQP1 immunofluorescence signals. Additional spectroscopic properties of SHL, such as absorbance, detection limits, photoswitching, and quantum yields, are detailed in the Supplemental Note section. The selectivity of SHL for $\mathrm{Li}^{+}$over other biologically relevant ions was confirmed through ion binding assays with the addition of excess ions $\left(\mathrm{Li}^{+}, \mathrm{Na}^{+}, \mathrm{K}^{+}, \mathrm{Cs}^{+}, \mathrm{Mg}^{2+}, \mathrm{Mn}^{2+}\right.$, $\mathrm{Cu}^{2+}$, or $\mathrm{Zn}^{2+}$ ). Results in Fig. 1B show that SHL had the highest affinity for $\mathrm{Li}^{+}$and relatively little response to similar monovalent ions, such as $\mathrm{Na}^{+}$and $\mathrm{K}^{+}$. The red-emitting properties and selectivity of SHL for $\mathrm{Li}^{+}$demonstrated that the emission observed in the cell was not due to autofluorescence or interaction of the sensor with other endogenous ions; the signal was specific to the MC(SHL) $-\mathrm{Li}^{+}$complex.

The AQP1 Cation Channel Is Permeable to $\mathrm{Li}^{+}$and Blocked by AqB011. AQP1-expressing and non-AQP control Xenopus oocytes were recorded by two-electrode voltage clamp in isotonic saline with $137 \mathrm{mM} \mathrm{Li}^{+}$substituted for standard physiologic $\mathrm{Na}^{+}$. Ion currents in isotonic $\mathrm{Li}^{+}$saline (Fig. 2A) were measured for human AQP1-expressing Xenopus oocytes and nonexpressing control oocytes before ("initial") and after treatment with a membrane-permeable analog of
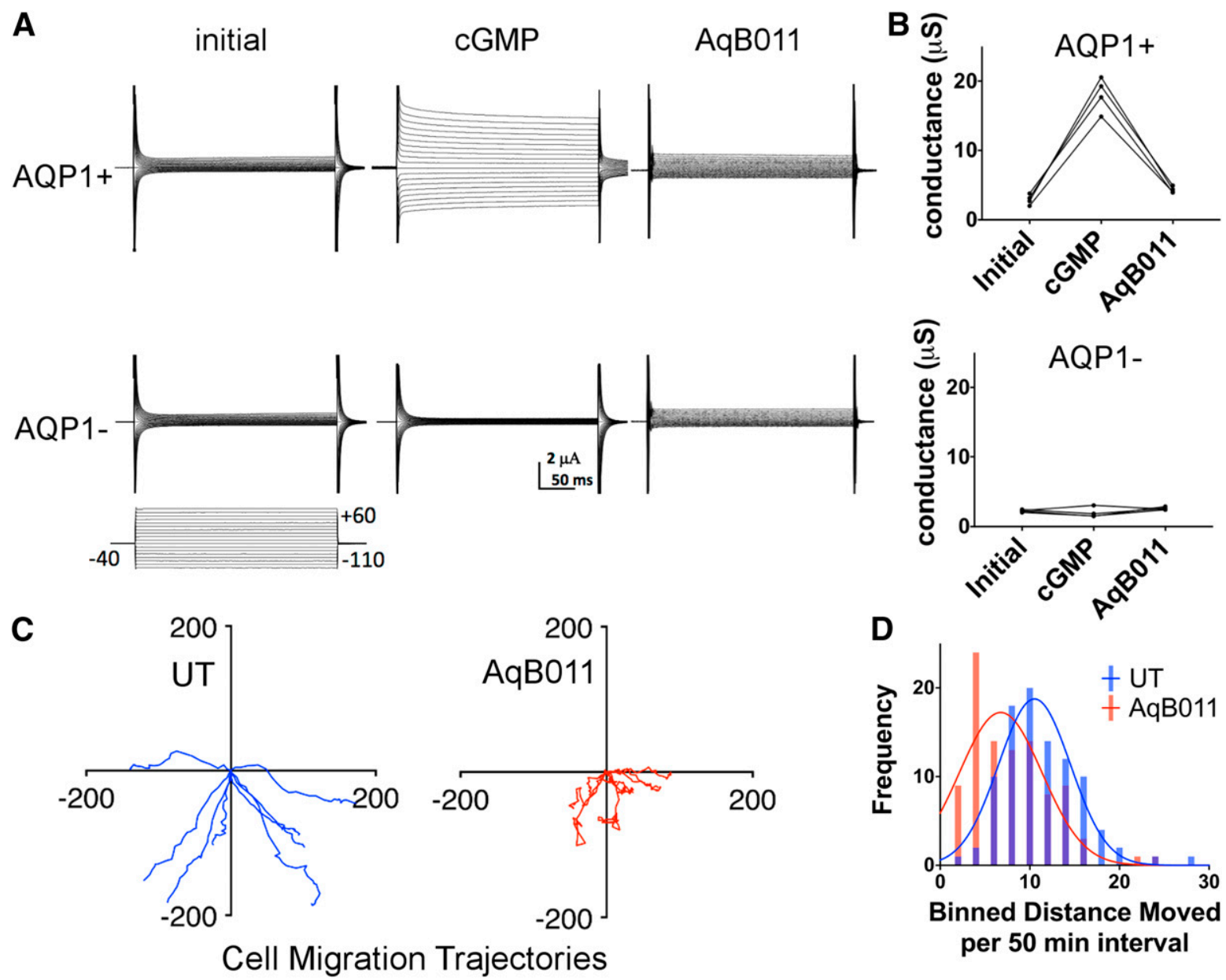

Fig. 2. AQP1 ion channels are permeable to $\mathrm{Li}^{+}$and blocked by the pharmacological agent $\mathrm{AqB} 011$, which also impairs migration in an $\mathrm{AQP1}$-expressing cancer cell line. (A) Two-electrode voltage clamp recordings in $\mathrm{Li}^{+}$isotonic saline of human AQP1-expressing (AQP1+) and nonexpressing control (AQP1-) Xenopus oocytes. After initial recordings (initial), ionic conductance responses were activated in AQP1+ but not AQP1- oocytes by 25 minutes after application of CPT-cGMP (cGMP). Post incubation in AqB011 (30 $\mu \mathrm{M} ; 2$ hours), the AQP1 conductance was unresponsive to the second application of cGMP (AqB011). (B) Trend plots illustrate responses for AQP+ oocytes measured before (initial) and after the first application of chlorophenylthio-cGMP (cGMP), and after the second application of CPT-cGMP following 2-hour incubation in saline with AqB011. Ion conductance responses were not observed in AQP1 control oocytes. (C) Migration trajectories for individual HT29 cells were monitored by live cell imaging at 50-minute intervals over 24 hours with (AqB011) and without AqB011 (UT) $(80 \mu \mathrm{M}) . n=8$ cells per treatment. (D) Compiled Gaussian distributions of individual cell distances moved per 50-minute interval and illustration of impaired rates of migration in the AqB011-treated HT29 cells (mean \pm S.E.M. was $5.69 \pm 0.54 \mu \mathrm{m} / \mathrm{h}$ with AqB011 and $8.83 \pm 0.22 \mu \mathrm{m} / \mathrm{h}$ with AqB011; $n=8$ per treatment group). UT, untreated. 
cGMP (chlorophenylthio-cGMP; see Materials and Methods for details), demonstrating $\mathrm{Li}^{+}$permeability of the ion conductance in AQP1-expressing oocytes and not in control oocytes. Oocytes were then incubated 2 hours in $30 \mu \mathrm{M}$ AqB011 and tested for reactivation by cGMP (“AqB011") in $\mathrm{Li}^{+}$saline. Results (Fig. 2B) showed that approximately $90 \%$ of the cGMPinduced current in AQP1-expressing oocytes was successfully blocked by AqB011, whereas control oocytes (AQP1-) lacked appreciable cGMP-activated current responses and showed no effect of the AqB011 inhibitor.

AqB011 Blocks Migration in AQP1-Expressing HT29 Colon Cancer Cells. Live-cell imaging was used to map the trajectories of cultured HT29 cells (Fig. 2C) to quantify migration rates in the presence and absence of the AQP1 ion channel blocker AqB011. Histogram summaries of the distances moved by individual cells per unit time interval show that the Gaussian distribution was substantially shifted to shorter distances in the presence of the AQP1 inhibitor (Fig. 2D), demonstrating that block of the ion channel activity impaired cell migration.

$\mathrm{Li}^{+}$Entry through Hot Spots in AQP1-Expressing HT29 Cells. The ability of SHL to detect $\mathrm{Li}^{+}$in live cells was investigated using confocal microscopy. HT29 colon cancer cells are known to have high AQP1 expression (Pei et al., 2016b) and were chosen as a useful model for testing cellular imaging of $\mathrm{Li}^{+}$permeation through nonselective cation channels. SHL (50 $\mu \mathrm{M}$ in physiologic saline) was incubated with the HT29 cells for 2 hours prior to imaging to allow loading of SHL into the cells. The cells were counterstained with Hoechst 33258 to label nuclei.

Illumination with green laser light activated the $\mathrm{MC}(\mathrm{SHL})-\mathrm{Li}^{+}$ complex, which resulted in a red fluorescence signal characteristic of this chemical interaction (Fig. 3A, ON1). Exposure of the cells to continuous white light for 10 minutes progressively shifted the signal to a low level of fluorescence, consistent with the expected photoswitching from the fluorescent $\mathrm{MC}(\mathrm{SHL})-\mathrm{Li}^{+}$complex to the nonfluorescent $\mathrm{SP}$ isomer. After prolonged white light illumination, the probe was reset to a responsive state by 10 -minute recovery in darkness, which allowed reactivation of the probe signal (ON2). Fluorescence intensity decreased as a single-phase decay function over time when cells were illuminated with standard white light (Fig. 3B), as illustrated by images taken at 2-minute intervals. The normalized signal intensity decreased from 100 relative
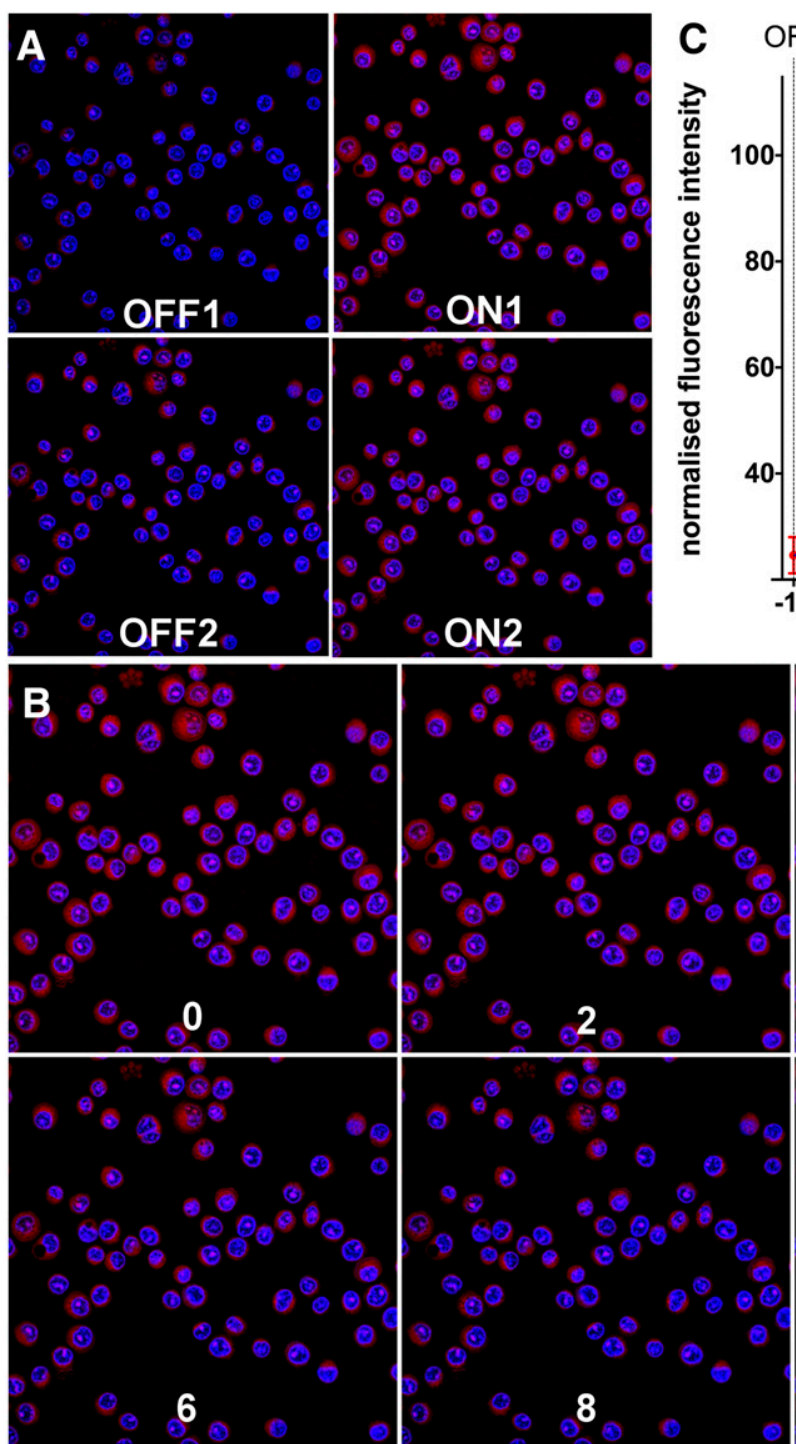
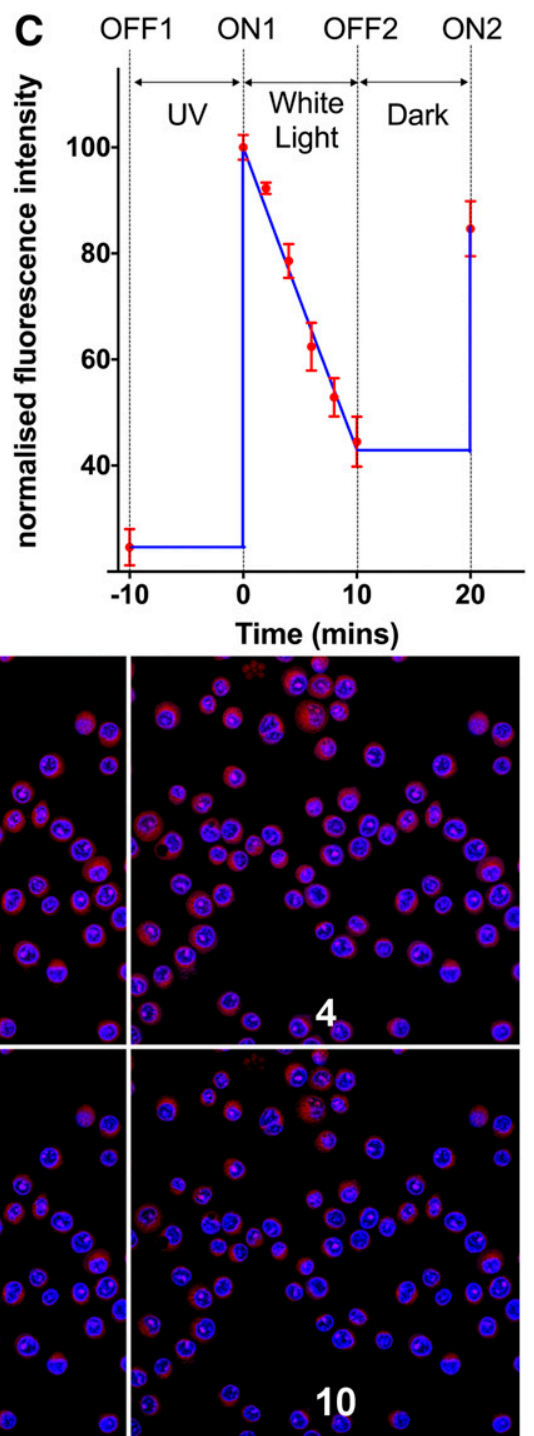

Fig. 3. Confocal time series for SHL signals in HT29 cells. (A) HT29 cells were incubated with $50 \mu \mathrm{M}$ SHL for 2 hours prior to imaging. Cell nuclei were labeled with Hoechst 33258 (blue). Four distinctive states of the sensor during the photoswitch cycles are illustrated. Cells were first illuminated under visible light radiation for 10 minutes to convert the majority of the sensor back to nonfluorescent SP isomer (OFF1). Then, cells were illuminated under UV light for 10 minutes to convert SP isomer to fluorescent $\mathrm{MC}(\mathrm{SHL})-\mathrm{Li}^{+}$complex (ON1), followed by exposure under white light for $10 \mathrm{~min}$ utes with measurement taken every 2 minutes (OFF2). Finally, cells were incubated in the dark for 10 minutes to allow the formation of the $\mathrm{MC}$ isomer and the binding of $\mathrm{Li}^{+}$to form the $\mathrm{MC}(\mathrm{SHL})-\mathrm{Li}^{+}$complex (OFF2). (B) Ten-minute white light illumination was applied to cells after ON1 state; images were taken every 2 minutes as illustrated. Red SHL signals gradually faded with time. (C) Red fluorescent signals were measured for individual cells in the field of view, and values were normalized to ON1 state. Data are the mean \pm S.E.M.; the $n$ value is 43 . A single-phase decay function was fitted to values between ON1 $(100 \%)$ and OFF2 $(44.51 \%)$ states; the half-life was determined to be 4.13 minutes, with a $\tau$ value estimated at 5.95 minutes. After 10-minute incubation in the dark, sensors converted back to the $\mathrm{MC}$ isomer, and the normalized intensity increased from $44.51 \%$ (OFF2) to $84.65 \%$ (ON2). 
fluorescence units (RFUs) to 44.51 RFUs after 10 minutes of visible light radiation (Fig. 3C). Under these experimental conditions, the half-life was determined to be 4.13 minutes with a $\tau$ value estimated at 5.95 minutes. Recovery in darkness for 10 minutes allowed the formation of the MC isomer. The binding of $\mathrm{Li}^{+}$regenerated the $\mathrm{MC}(\mathrm{SHL})-\mathrm{Li}^{+}$complex at a normalized intensity of 84.65 RFUs (Fig. 3C; ON2). Repeated cycles of photoswitching performed on the same cells gave reproducible changes in fluorescence, demonstrating the ability of SHL to photoswitch reversibly in living cells. This innovation defines a new probe for monitoring changes in intracellular $\mathrm{Li}^{+}$in a biologic sample over time without loss of sensitivity imposed by photobleaching of a sensor. The photoswitching property allows repeated comparisons of function across multiple experimental treatments and provides additional advantages for biologic assays in which sample availability can be limited.

Distinctive punctate signals, referred to here as lithium "hot spots," were observed in HT29 cells when imaged in $\mathrm{Li}^{+}$-containing saline (Fig. 4A, 1). A loss of hot spot events was observed after treatment with the AQP1 ion channel antagonist AqB011 (20 $\mu \mathrm{M}$ for 2 hours), after which only a faint background fluorescence was observed (Fig. 4A, 2). The removal of $\mathrm{Li}^{+}$from the extracellular saline by equimolar substitution with the $\mathrm{TEA}^{+}$ion also caused a loss of hot spots (Fig. 4A, 3), showing that the observed events resulted from $\mathrm{Li}^{+}$ion entry. In saline with $\mathrm{TEA}^{+}$, application of the blocker AqB011 had no additional effect on hot spot activity (Fig. 4A, 4). The fluorescent signal for the entire cell was reduced 2-fold in HT29 cells when $\mathrm{Li}^{+}$entry was compromised by pharmacological block of the ion channel with AqB011 or by removal of extracellular $\mathrm{Li}^{+}$ion via replacement with other cations as chloride salts (Fig. 4B). Collectively, these data confirmed that the bright punctate $\mathrm{Li}^{+}$signals depended on the presence of extracellular $\mathrm{Li}^{+}$and the presence of functional AQP1 ion channels, and ruled out the possibility that hot spots were indirectly due to nonspecific interactions with other intracellular cations or entry of $\mathrm{Li}^{+}$through other cation pathways. The most parsimonious interpretation is that the lithium hot spots represent $\mathrm{Li}^{+}$entry across the plasma membrane through AQP1 cation channels.

Knockdown of AQP1 expression with small interfering RNA (siRNA) resulted in a dramatic loss of red $\mathrm{Li}^{+}$hot spots, specifically in transfected HT29 cells (labeled green with cotransfected siGLO transfection indicator) and not in nontransfected cells in the same culture plate (Fig. 4C). The fluorescence intensity of signals from the SHL $\mathrm{Li}^{+}$probe (Fig. 4D) and the levels of AQP1 transcript assessed by quantitative PCR (Fig. 4E) both were reduced significantly with AQP1-siRNA treatment, but not with control scrambled siRNA treatment. These data confirm that in HT29 cells, the appearance of $\mathrm{Li}^{+}$hot spots requires the expression of AQP1 channels.

$\mathrm{Li}^{+}$Hot Spots Were Not Observed in SW620 Cells Lacking High Levels of AQP1 Expression. The role of AQP1 ion channels in mediating the lithium hot spot events was tested by comparison with another colon cancer cell line (SW620) which is similar to HT29 in having an adherent epithelial phenotype (Fogh et al., 1977) but different in that rates of migration are slower. Levels of AQP1 expression were approximately 2.6-fold lower in SW620 than in HT29 cells (Fig. 5, A and B); this finding is further supported by the reverse-transcription PCR data (Fig. 5C). HT29 cells and
SW620 cells were preincubated in SHL for 2 hours, transferred into $\mathrm{Li}^{+}$-substituted saline, and imaged. Results show that the lithium hot spots are more abundant and brighter in HT29 cells (Fig. 5D, 1-3) than in SW620 cells (Fig. 5D, 4-6). In migrating HT29 cells, lithium hot spots are concentrated in leading edges (Fig. 5D, 2 and 3) in contrast to the uniform distribution seen in nonmigrating cells (Fig. 5D, 1). This observation is consistent with the known clustering of AQP1 channels in the leading edges of specific classes of cells during migration (McCoy and Sontheimer, 2007), where these channels are proposed to facilitate fluid movements needed for volume changes during extension, and possibly to compensate for changes in osmotic pressure associated with actin polymerization and depolymerization (Hu and Verkman, 2006).

AQP1 expression and localization were determined by immunofluorescent imaging using confocal microscopy. AQP1 protein was immunolabeled with anti-AQP1 primary antibody and green fluorescent AlexaFluor 488 secondary antibody and visualized by 488-nm laser excitation. HT29 cells demonstrated high AQP1 signal intensities as compared with SW620 cells (Fig. 6, A and B). Comparison with SW620 cells confirmed that a reduced abundance of lithium hot spots correlated with lower levels of AQP1 expression. In combination, results here based on pharmacology, ion substitution, and a comparison of cell lines with different levels of AQP1 expression provide evidence that the lithium hot spots measured by the novel probe SHL mark the locations of active AQP1 ion channels.

Lithium Hot Spots Are Colocalized with AQP1 Channels in HT29 Cells. The spatial correlation between the locations of the lithium hot spots and AQP1 channels was assessed using confocal microscopy. Signal intensities using Z-stack compiled images were measured as a function of distance across the cell diameter (indicated by straight lines crossing the cell centers; two cross-sections per cell). Signals were plotted as a function of $\mathrm{X}-\mathrm{Y}$ distance to quantify the correspondence between the $\mathrm{SHL} \mathrm{Li}{ }^{+}$fluorescence intensity [red channel; $\mathrm{MC}(\mathrm{SHL})-\mathrm{Li}^{+}$complex] and the AQP1 protein signal intensity (green channel; immunofluorescence). Results in Fig. 6C show that the two fluorescence signals were strongly colocalized in HT29 cells (with superimposed red and green signals represented as yellow), yielding RFUs ranging from 50 to 200 that were consistent with data shown in Fig. 5A. The spatial profiles of the red and green signals across the cell diameter are illustrated by plots of signal intensity (Fig. 6D). $\mathrm{Li}^{+}$and AQP1 signals in HT29 cells were strongly correlated, with $R^{2}$ values ranging 0.61 to 0.68 . In contrast, SW620 cells (Fig. 6D) showed low signal intensities and poor spatial correlation, with signal values mainly at $0-50$ RFUs and $R^{2}$ values ranging from 0.06 to 0.09 . This work opens new avenues for the potential realtime visualization of cation channel function and the localization of active channel domains in living cells, and provides additional insight into the relevance of cation channels such as AQP1 in dynamic cellular responses, such as migration.

Lithium Hot Spots Are Dynamic When Imaged in HT29 Cells. The ability of SHL to detect dynamic $\mathrm{Li}^{+}$entry through AQP1 was tested using a 300-second time-lapse video of an SHL-loaded cell directly after perfusion with $\mathrm{Li}^{+}$-substituted extracellular saline. The intensity of $\mathrm{Li}^{+}$hot spots increased during the first half of the recording, then cycled between increasing and decreasing signal intensities during the second half (Fig. 7). The montage shows a time series for a $2 \times 3-\mu \mathrm{m}$ field of view (rectangle), illustrating the dynamic fluorescence 

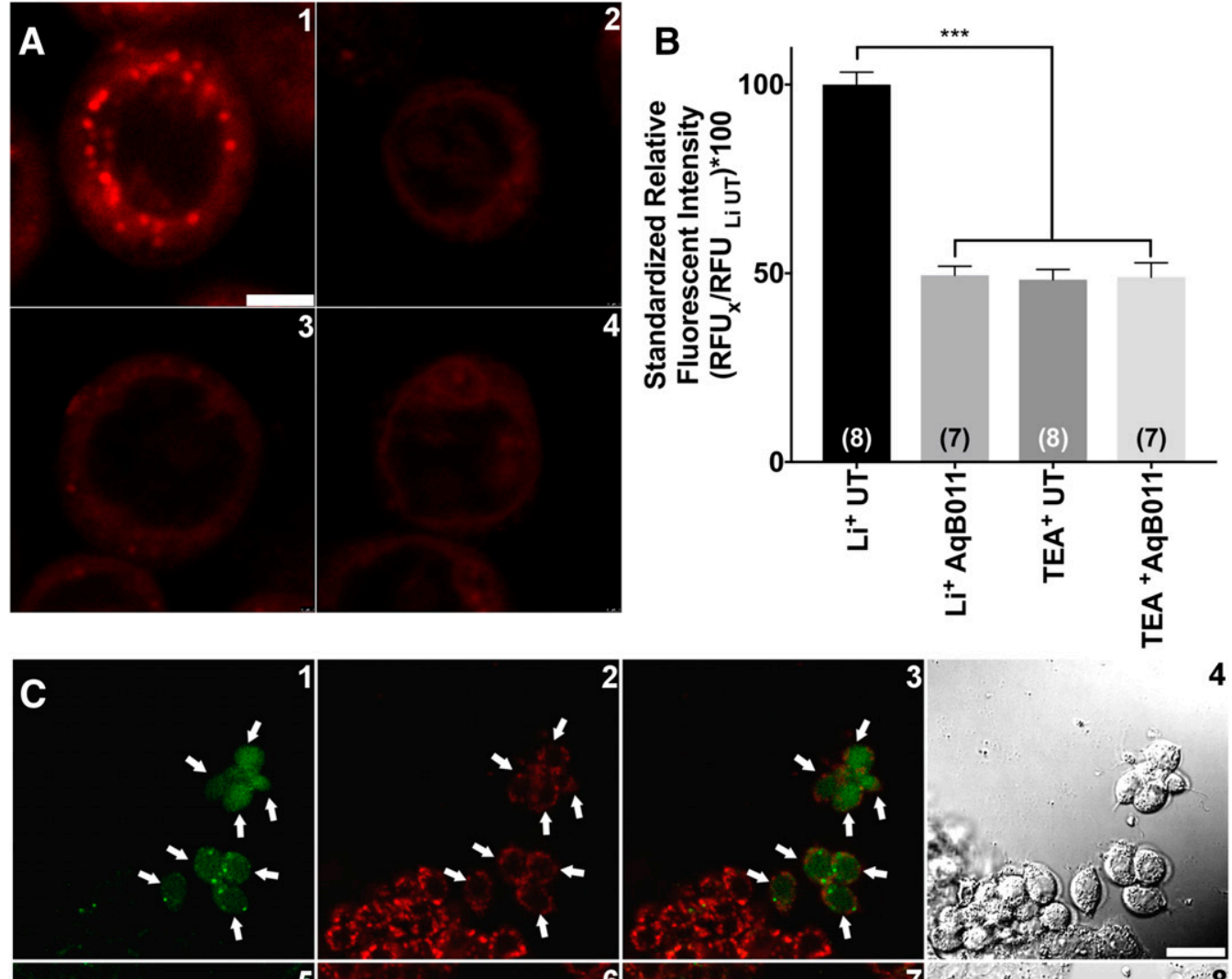

4
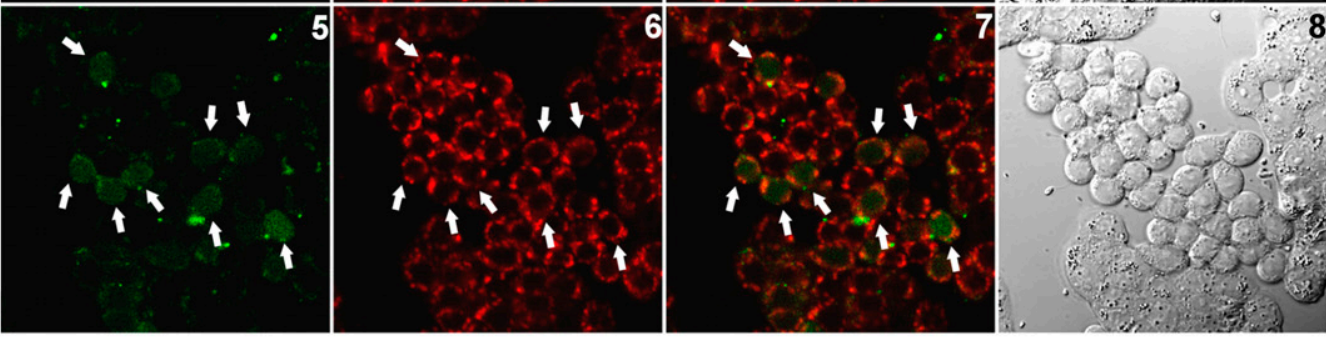

D

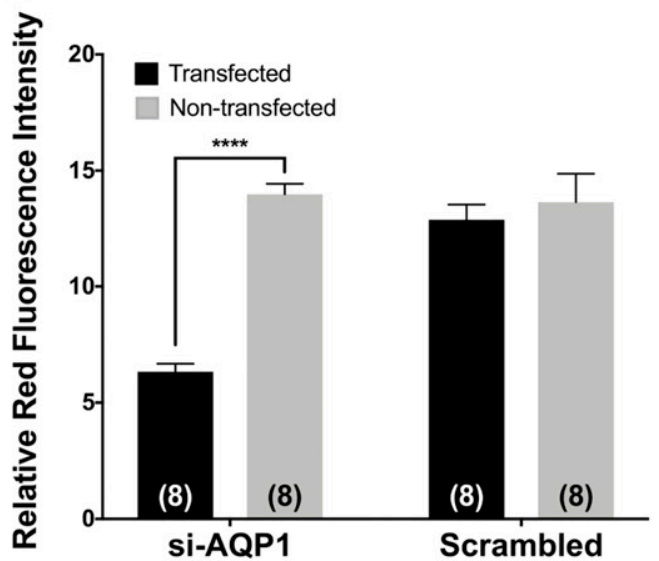

E

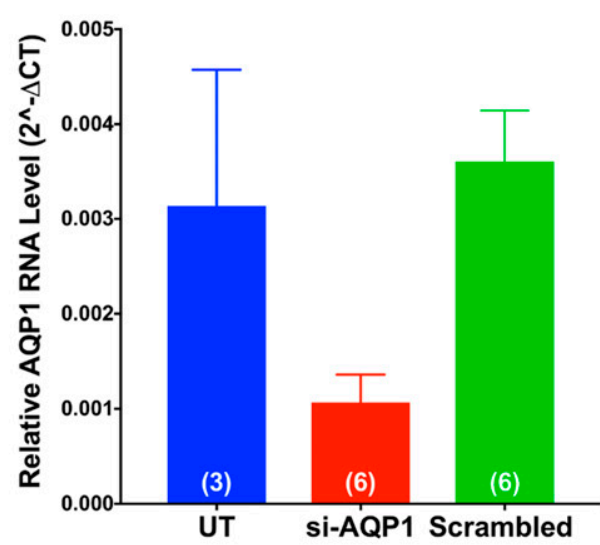

Fig. 4. Lithium hot spot signals depend on functional AQP1 channels. (A) Distinctive punctate $\mathrm{Li}^{+}$hot spots were observed in $\mathrm{HT} 29$ cells imaged in Li ${ }^{+}$substituted extracellular saline (1). In cells that were pretreated with $20 \mu \mathrm{M} \mathrm{AqB011}$ for 2 hours, $\mathrm{Li}^{+}$hot spots were not observed (2). Similar losses of hot spot events were observed after the removal of $\mathrm{Li}^{+}$from the extracellular saline by equimolar substitution of TEA $(3)$. Pretreatment with $20 \mu \mathrm{M}$ AqB011 ( 2 hours) caused no further change in the signal in the absence of extracellular $\mathrm{Li}^{+}$(4). (B) $\mathrm{Li}^{+}$-selective fluorescent signals were quantified by measuring red fluorescence intensities of individual cells. Intensities were normalized to those of HT29 cells imaged in $\mathrm{Li}^{+}$saline. $\mathrm{Li}^{+}$entry was significantly compromised by pharmacological block (AqB011) or removal of $\mathrm{Li}^{+}$ion from the saline by equimolar replacement with other cations, such as TEA ${ }^{+}$. Significant differences were analyzed by comparing the $\mathrm{Li}^{+} \mathrm{AqB011}$, TEA ${ }^{+} \mathrm{UT}$, and TEA ${ }^{+} \mathrm{AqB} 011$ groups to the $\mathrm{Li}^{+} \mathrm{UT}_{\text {group }}(\mathrm{see}$ Materials and Methods for details). (C) HT29 cells were transfected with either siRNA targeting AQP1 (si-AQP1, upper panels) or scrambled siRNA (scrambled, lower panels) before confocal imaging. Cells were preincubated in transfection indicator siGLO Green (green, 1 and 5) and SHL (red, 2 and 6). Stacked images of both green and red channels are illustrated in 3 and 7 , and bright field images are illustrated in 4 and $8 . \mathrm{Li}^{+}$signals were impaired in cells successfully transfected with AQP1 siRNA (cells with green nucleus, 3) but not in cells transfected with scrambled siRNA (cells with green nucleus, 7). (D) $\mathrm{Li}^{+}{ }^{-}$selective 


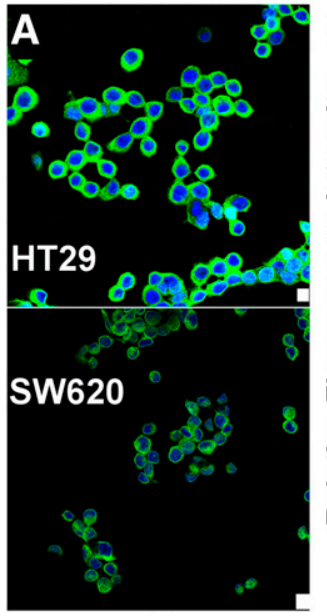

B
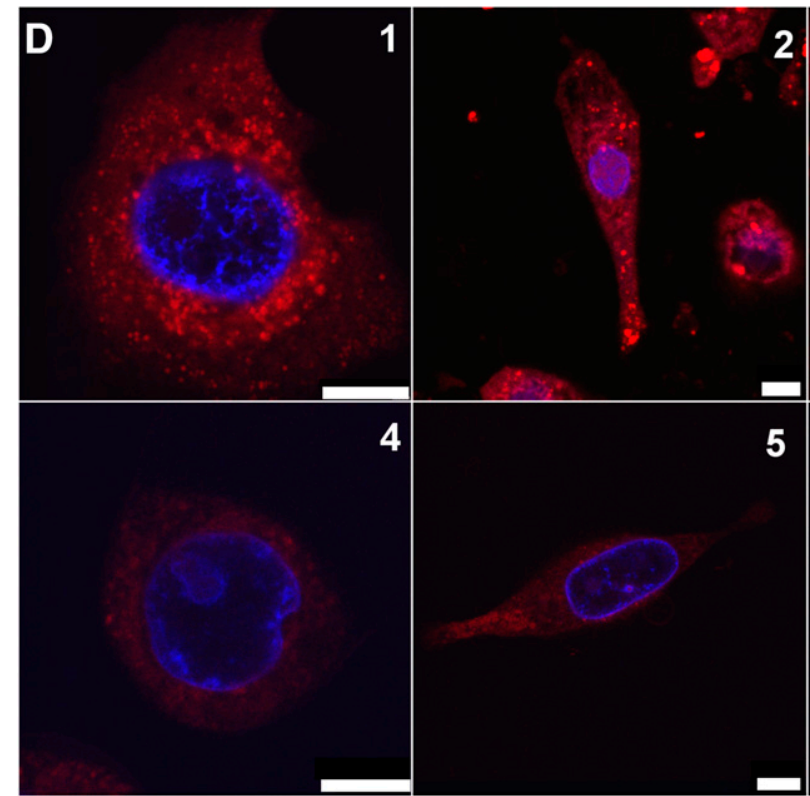

2

C

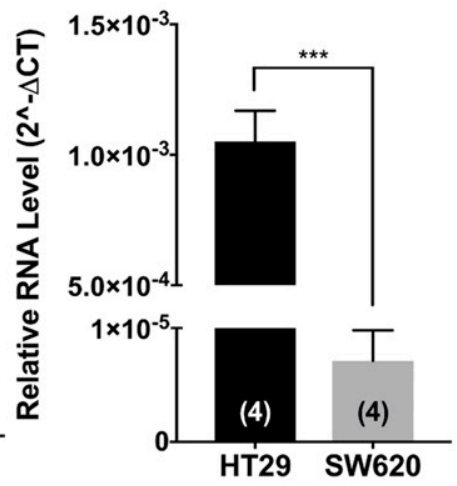

3

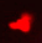

4

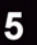

5

6
Fig. 5. Characterization of lithium hot spots in AQP1-expressing and AQP1-deficient cells. (A) Cells were labeled with Hoechst nuclear stain (blue) and anti-AQP1 antibody (tagged with fluorescent secondary antibody; green). (B) Anti-AQP1 immunofluorescence intensities for HT29 cells were approximately 2.6 -fold higher than in SW620 cells. (C) AQP1 RNA levels measured by reversetranscription quantitative PCR were more than 100 -fold lower in SW620 cells as compared with HT29 cells. (D) HT29 and SW620 cells were loaded with SHL for 2 hours prior to imaging. A strong $\mathrm{Li}^{+}$signal was observed in all HT29 cells $(1,2,3)$ as compared with the minimal $\mathrm{Li}^{+}$signals observed in SW620 cells $(4,5,6)$. In nonmigrating HT29 cells, $\mathrm{Li}^{+}$hot spots appeared as widely distributed across the cell (1). In migrating HT29 cells, $\mathrm{Li}^{+}$hot spots were concentrated at leading edges of the cells $(2,3)$. White scale bars indicate $5 \mu \mathrm{m}$. Significant differences were analyzed by unpaired $t$ test and are reported as $P<0.001$ (***) (see Materials and Methods for details). emission properties. A movie depicting $\mathrm{Li}^{+}$hot spot activity in HT29 cells in real time is available as Supplemental Material (Supplemental Video).

\section{Discussion}

Work with confocal imaging presented here is the first to demonstrate the use of a new $\mathrm{Li}^{+}$-selective photoswitchable probe as a tool for monitoring nonselective cation entry in living cells, with AQP1 ion channels of migrating cancer cells selected as a model for illustrating feasibility and potential significance. Nonselective monovalent cation channel activity was monitored with the probe SHL, which is selective for $\mathrm{Li}^{+}$. Lithium hot spots were abundant in HT29 colon cancer cells expressing high levels of AQP1 and rare in SW620 colon cancer cells which have comparatively little AQP1. The spatial localization of $\mathrm{Li}^{+}$hot spots at the leading edges of HT29 cells was an exciting observation, fitting the predicted location of AQP1 ion channels. Future studies characterizing the dynamic temporal and spatial properties of ion fluxes in migrating cells at higher resolution will be of interest.

The initial proposal that AQP1 works as a nonselective cation channel in addition to its known role as a water channel (Yool et al., 1996) generated controversy (Agre et al., 1997; Tsunoda et al., 2004). Subsequent analyses confirmed the capacity of AQP1 to function as a dual water and ion channel, showing the ion channel activity was gated directed by intracellular cGMP and indirectly regulated by intracellular signaling cascades including tyrosine phosphorylation (Anthony et al., 2000; Saparov et al., 2001; Boassa and Yool, 2003; Campbell et al., 2012), but left unclear the physiologic relevance of the dual water and ion channel function (Saparov et al., 2001). Recent work has since

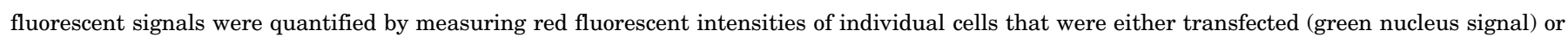

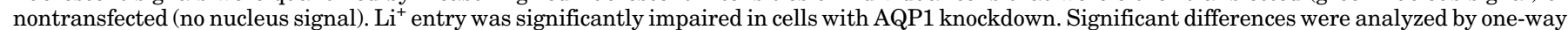

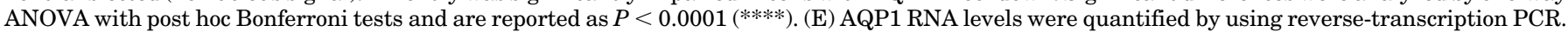

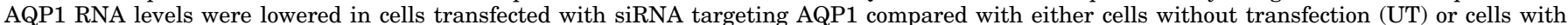
scrambled siRNA transfection (scrambled). UT, untreated. 


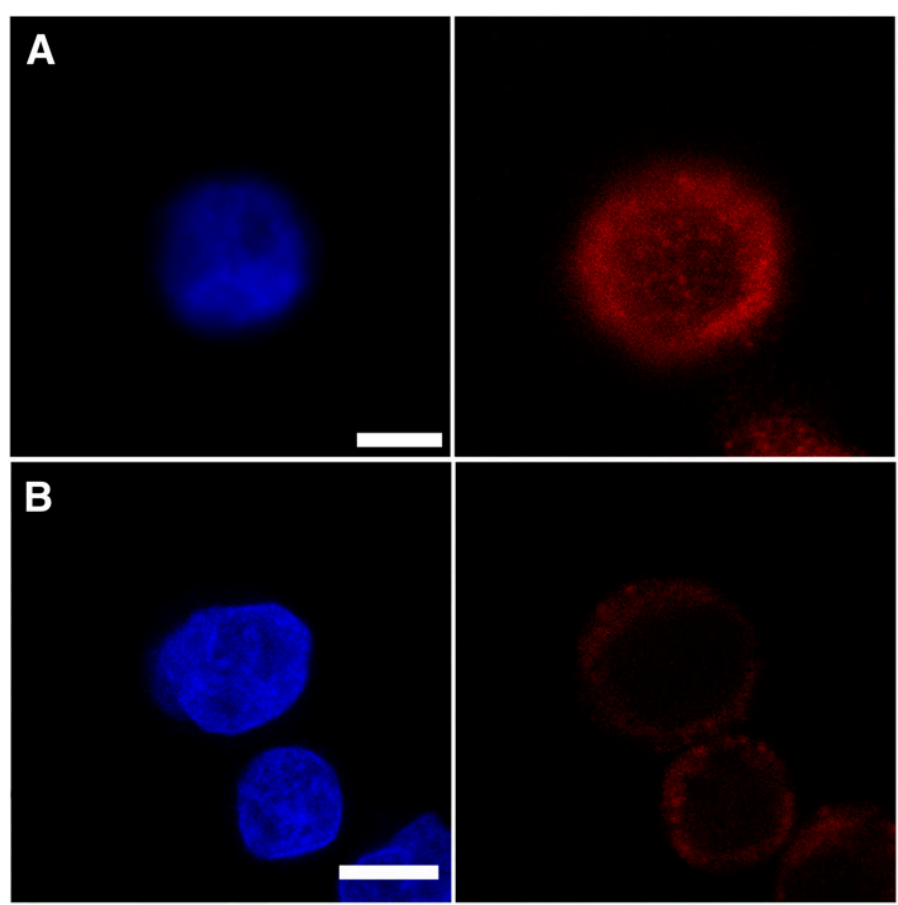

C
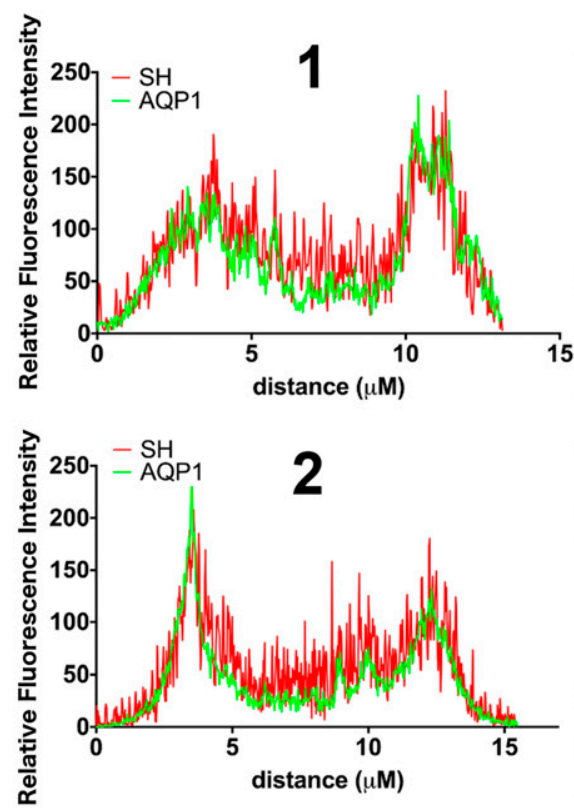
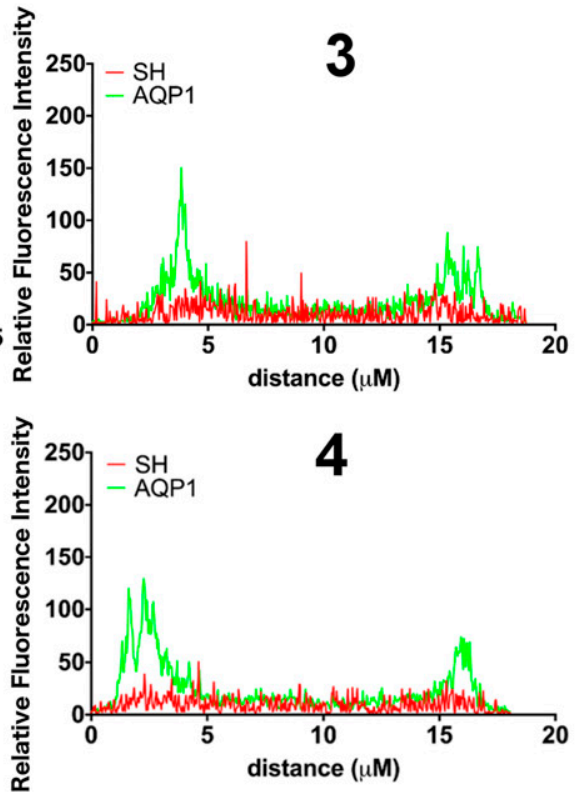

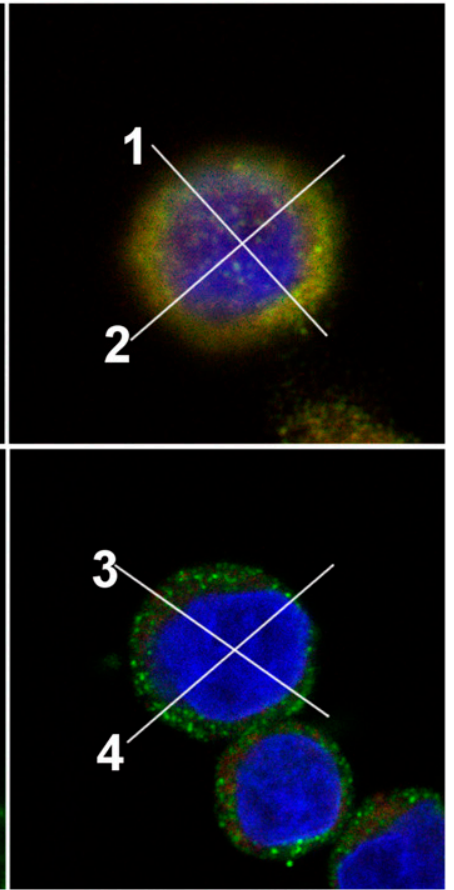

D

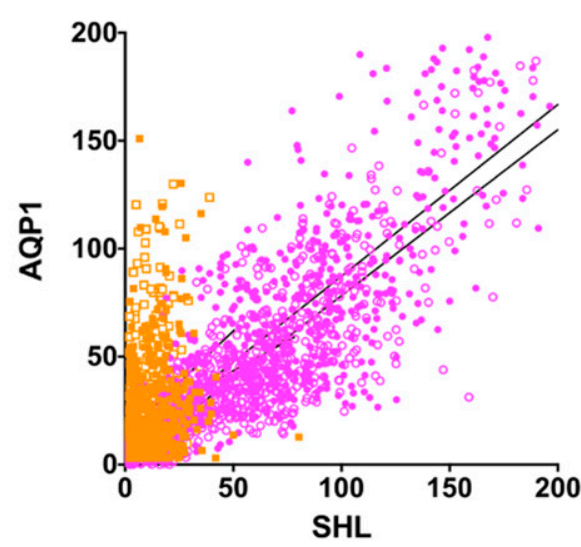

$\approx \mathrm{HT} 29-\mathrm{HT} 29 \approx \mathrm{SW} 620-\mathrm{SW} 62 \mathrm{O}$

$\begin{array}{lllll}R^{2} & 0.6105 & 0.6818 & 0.06073 & 0.08837\end{array}$

Fig. 6. Quantitative confocal analyses of the colocalization of AQP1 and $\mathrm{Li}^{+}$hot spots. HT29 cells (A) and SW620 cells (B) were preincubated with SHL (red) and then fixed and labeled with AQP1 primary antibody and AlexaFluor-488-conjugated secondary antibody (green). Nuclei were stained with Hoechst (blue). Both the $\mathrm{Li}^{+}$and AQP1 signals were at higher intensities in HT29 cells than in SW620 cells. In the far-right panels, all three signal bandwidth images are combined, with colocalized red and green signals seen as yellow. Fluorescence signals from the MC(SHL)-Li ${ }^{+}$complex and AQP1 were strongly colocalized in HT29 cells but not in SW620 cells. (C) Two cross-sections through cell centers were selected (labeled 1 and 2 for HT29, 3 and 4 for SW620). The red $\mathrm{Li}^{+}$and green AQP1 signal intensities in the cross-sectional lines were plotted as a function of X-Y distance across the cell. HT29 cells showed robust levels and a strong correlation between $\mathrm{Li}^{+}$and AQP1 signal intensities, which was not seen in SW620 cells. (D) Linear regression analyses quantified the correlation between $\mathrm{Li}^{+}$signal and AQP1 signal intensities in HT29 cells (pink) and SW620 cells (orange) for data from (C). $R^{2}$ values calculated using GraphPad Prism 7 were 0.61 and 0.68 for HT29 cell cross sections, and 0.06 and 0.09 for SW620 cells.

demonstrated that the AQP1 ion conductance is essential for rapid cell movement in a subset of cancer cells which show high metastasis or invasiveness (Kourghi et al., 2016; Pei et al., 2016b), demonstrating a functional role for the AQP1 ion channel.

AQP1 channels are not the only pathway for $\mathrm{Li}^{+}$transport across cell membranes. $\mathrm{Li}^{+}$is also conducted through voltage-gated $\mathrm{Na}^{+}$channels (Hille, 1972; Richelson, 1977; Timmer and Sands, 1999) and the $\mathrm{Na}^{+}$-proton exchanger (Lenox et al., 1998). Some of the $\mathrm{Li}^{+}$signal described here could involve additional channels or transporters. However, the alternative hypothesis that the lithium signal observed in HT29 cancer cells is due entirely to mechanisms unrelated to 


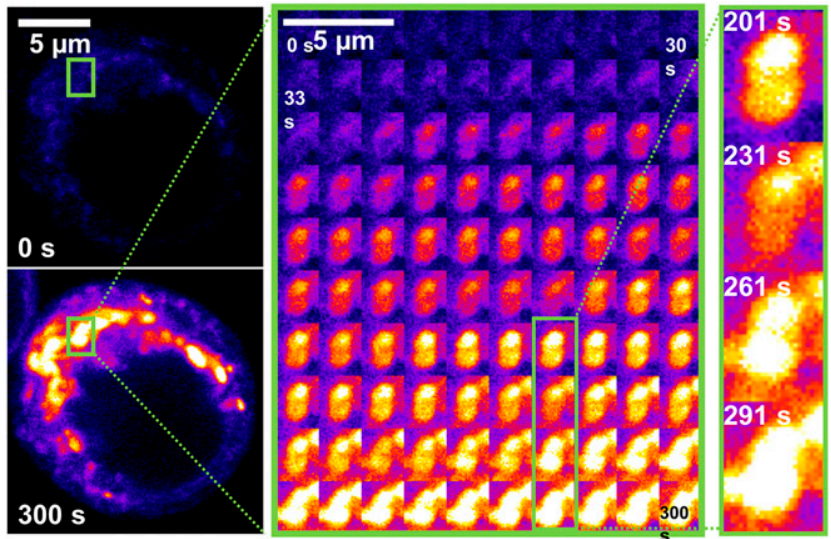

Fig. 7. Dynamic properties of $\mathrm{Li}^{+}$hot spots illustrating ON/OFF SHL probe transitions in a living HT29 cell. HT29 cells preloaded with SHL were imaged for 100 frames at 3-second intervals. Extracellular saline was replaced with $\mathrm{Li}^{+}$saline at time 0 . Multiple $\mathrm{Li}^{+}$hot spots were activated, as illustrated in the left panels at time 0 and 300 seconds. Images were cropped to show higher magnification views of two discrete $\mathrm{Li}^{+}$hot spots (middle panel) as a time-lapse montage, illustrating the independent $\mathrm{ON} / \mathrm{OFF} / \mathrm{ON}$ transitions of the hot spots (inset, right).

AQP1 seems unlikely for several reasons. First, results here show that pharmacological inhibition with the AQP1 ion channel blocker AqB011 significantly diminished the $\mathrm{Li}^{+}$signal to a level similar to the response observed in cells imaged in saline with $\mathrm{TEA}^{+}$(which does not bind to SHL). Other AQP modulators in the library of bumetanide derivatives that include AqB011 have been shown to be selective for specific AQP classes without off-target effects on other signaling and transport mechanisms (Migliati et al., 2009; Yool et al., 2013). Second, the punctate $\mathrm{Li}^{+}$signal pattern was not evident in SW620 cells that have low levels of AQP1 expression but otherwise express various channels and transporters required for basic cellular function and low-level motility. Third, the colocalization of AQP1 expression and $\mathrm{Li}^{+}$signals showed a robust correlation.

Since SHL passively diffuses across the membrane, it should achieve a reasonably uniform distribution on the cytoplasmic side. Punctate $\mathrm{Li}^{+}$hot spots indicate local areas of $\mathrm{Li}^{+}$entry and accumulation. As shown using the oocyte expression system, AQP1 ion channels mediate $\mathrm{Li}^{+}$influx. In combination with results of pharmacological block and siRNA knockdown, data here support the interpretation that the interaction of $\mathrm{Li}^{+}$ with SHL resulting in hot spots occurs in the vicinity of active AQP1 ion channels. The remaining intracellular SHL throughout areas without substantial $\mathrm{Li}^{+}$influx would remain predominantly in the nonfluorescent form, consistent with the low-level background fluorescence.

The increased incidence of hot spots in cellular protrusions was consistent with work from others indicating that AQP1 is localized at the leading edges in migrating cells (McCoy and Sontheimer, 2007). The slow temporal resolution used here for image capture was sufficient to illustrate the dynamic property of the $\mathrm{Li}^{+}$hot spots, which turned on and off over time (as shown in Fig. 7). The observed on/off dynamics of SHL in AQP1-expressing cells was limited by our confocal microscopy setup to a minimal image acquisition rate of 3 seconds per frame; optimization will be needed to enable better evaluations of channel kinetics. Our focus on AQP1 for testing the SHL probe may have benefitted from the usually slow gating properties of the AQP1 ion channel, which once opened, shows long bursts persisting for hundreds of milliseconds and sets of bursts lasting for seconds (Anthony et al., 2000).

Evidence that AQP1 is not just a water channel but also functions as a monovalent cation channel contributes to our understanding of the diverse mechanisms that govern cell migration. Looking ahead to translational applications, we propose that the lithium sensor will be useful for investigating cation channel function in many types of living cells, including sensory cells, immune cells, cancer cells, and more. The AQP1 ion channel itself is an attractive candidate for development of new therapeutics, and the $\mathrm{Li}^{+}$sensor SHL could be a powerful tool in high-throughput screening for new pharmacological agents that might ultimately help manage metastasis in aggressive AQP1-dependent cancers.

\section{Acknowledgments}

The authors acknowledge Dr. Xiaozhou Zhang for useful discussions, and Dr. Agatha Labrinidis and Dr. Jane Sibbons at Adelaide Microscopy for training and access to core microscopy facilities.

\section{Authorship Contributions}

Participated in research design: Pei, Heng, Abell, Yool.

Conducted experiments: Pei, Heng, De Ieso, Sylvia, Kourghi,

Nourmohammadi.

Contributed new reagents or analytic tools: Pei, Heng, Abell.

Performed data analysis: Pei, Heng, De Ieso, Sylvia, Kourghi, Nourmohammadi, Yool.

Wrote or contributed to the writing of the manuscript: Pei, Heng, De Ieso, Sylvia, Kourghi, Nourmohammadi, Abell, Yool.

\section{References}

Agre P, Lee MD, Devidas S, and Guggino WB (1997) Aquaporins and ion conductance. Science 275:1490, author reply 1492 .

Agre P, Preston GM, Smith BL, Jung JS, Raina S, Moon C, Guggino WB, and Nielsen S (1993) Aquaporin CHIP: the archetypal molecular water channel. Am J Physiol 265:F463-F476.

Anthony TL, Brooks HL, Boassa D, Leonov S, Yanochko GM, Regan JW, and Yool AJ (2000) Cloned human aquaporin-1 is a cyclic GMP-gated ion channel. Mol Pharmacol 57:576-588.

Boassa D and Yool AJ (2003) Single amino acids in the carboxyl terminal domain of aquaporin-1 contribute to cGMP-dependent ion channel activation. BMC Physiol 3:12.

Campbell EM, Birdsell DN, and Yool AJ (2012) The activity of human aquaporin 1 as a cGMP-gated cation channel is regulated by tyrosine phosphorylation in the carboxyl-terminal domain. Mol Pharmacol 81:97-105.

Dorward HS, Du A, Bruhn MA, Wrin J, Pei JV, Evdokiou A, Price TJ, Yool AJ, and Hardingham JE (2016) Pharmacological blockade of aquaporin-1 water channel by AqB013 restricts migration and invasiveness of colon cancer cells and prevents endothelial tube formation in vitro. J Exp Clin Cancer Res 35:36.

Fogh J, Fogh JM, and Orfeo T (1977) One hundred and twenty-seven cultured human tumor cell lines producing tumors in nude mice. J Natl Cancer Inst 59:221-226.

Friedl P and Wolf K (2003) Tumour-cell invasion and migration: diversity and escape mechanisms. Nat Rev Cancer 3:362-374.

Heng S, Mak AM, Kostecki R, Zhang X, Pei J, Stubing DB, Ebendorff-Heidepriem H, and Abell AD (2017) Photoswitchable calcium sensor: 'On'-'Off' sensing in cells or with microstructured optical fibers. Sens Actuators B Chem 252:965-972.

Heng S, Nguyen M, Kostecki R, Monro TM, and Abell AD (2013) Nanoliter-scale, regenerable ion sensor: sensing with a surface functionalized microstructured optical fiber. RSC Adv 3:8308-8317.

Hille B (1972) The permeability of the sodium channel to metal cations in myelinated nerve. J Gen Physiol 59:637-658.

$\mathrm{Hu} \mathrm{J}$ and Verkman AS (2006) Increased migration and metastatic potential of tumor cells expressing aquaporin water channels. FASEB J 20:1892-1894.

King LS, Kozono D, and Agre P (2004) From structure to disease: the evolving tale of aquaporin biology. Nat Rev Mol Cell Biol 5:687-698.

Klajn R (2014) Spiropyran-based dynamic materials. Chem Soc Rev 43:148-184

Kolmakov K, Belov VN, Bierwagen J, Ringemann C, Müller V, Eggeling C, and Hell SW (2010) Red-emitting rhodamine dyes for fluorescence microscopy and nanoscopy. Chemistry 16:158-166.

Kourghi M, Pei JV, De Ieso ML, Flynn G, and Yool AJ (2016) Bumetanide derivatives AqB007 and AqB011 selectively block the aquaporin-1 ion channel conductance and slow cancer cell migration. Mol Pharmacol 89:133-140.

Krummel MF, Bartumeus F, and Gérard A (2016) T cell migration, search strategies and mechanisms. Nat Rev Immunol 16:193-201.

Lenox RH, McNamara RK, Papke RL, and Manji HK (1998) Neurobiology of lithium: an update. J Clin Psychiatry 59 (Suppl 6):37-47.

McCoy E and Sontheimer H (2007) Expression and function of water channels (aquaporins) in migrating malignant astrocytes. Glia 55:1034-1043. 
Migliati E, Meurice N, DuBois P, Fang JS, Somasekharan S, Beckett E, Flynn G, and Yool AJ (2009) Inhibition of aquaporin-1 and aquaporin-4 water permeability by a derivative of the loop diuretic bumetanide acting at an internal pore-occluding binding site. Mol Pharmacol 76:105-112.

Olson MF and Sahai E (2009) The actin cytoskeleton in cancer cell motility. Clin Exp Metastasis 26:273-287.

Papadopoulos MC, Saadoun S, and Verkman AS (2008) Aquaporins and cell migration. Pflugers Arch 456:693-700.

Pei JV, Burton JL, Kourghi M, De Ieso ML, and Yool AJ (2016a) Drug discovery and therapeutic targets for pharmacological modulators of aquaporin channels, in Aqua porins in Health and Disease: New Molecular Targets for Drug Discovery (Soveral G, Casinin A, and Nielsen S eds) pp 275-297, CRC Press, Oxfordshire, UK.

Pei JV, Kourghi M, De Ieso ML, Campbell EM, Dorward HS, Hardingham JE, and Yool AJ (2016b) Differential inhibition of water and ion channel activities of mammalian aquaporin-1 by two structurally related bacopaside com pounds derived from the medicinal plant bacopa monnieri. Mol Pharmaco 90:496-507.

Petrie RJ, Doyle AD, and Yamada KM (2009) Random versus directionally persistent cell migration. Nat Rev Mol Cell Biol 10:538-549.

Richelson E (1977) Lithium ion entry through the sodium channel of cultured mouse neuroblastoma cells: a biochemical study. Science 196:1001-1002.

Rivera-Fuentes P, Wrobel AT, Zastrow ML, Khan M, Georgiou J, Luyben TT, Roder JC, Okamoto K, and Lippard SJ (2015) A far-red emitting probe for unambiguous detection of mobile zinc in acidic vesicles and deep tissue. Chem Sci (Camb) 6:1944-1948.
Saparov SM, Kozono D, Rothe U, Agre P, and Pohl P (2001) Water and ion permeation of aquaporin-1 in planar lipid bilayers. Major differences in structural determinants and stoichiometry. J Biol Chem 276:31515-31520.

Smith E, Palethorpe HM, Tomita Y, Pei JV, Townsend AR, Price TJ, Young JP, Yool AJ, and Hardingham JE (2018) The purified extract from the medicinal plant Bacopa monnieri, bacopaside II, inhibits growth of colon cancer cells in vitro by inducing cell cycle arrest and apoptosis. Cells 7.

Stubing DB, Heng S, and Abell AD (2016) Crowned spiropyran fluoroionophores with a carboxyl moiety for the selective detection of lithium ions. Org Biomol Chem 14:3752-3757.

Timmer RT and Sands JM (1999) Lithium intoxication. J Am Soc Nephrol 10:666-674.

Tsunoda SP, Wiesner B, Lorenz D, Rosenthal W, and Pohl P (2004) Aquaporin-1, nothing but a water channel. J Biol Chem 279:11364-11367.

Yool AJ, Morelle J, Cnops Y, Verbavatz JM, Campbell EM, Beckett EA, Booker GW, Flynn G, and Devuyst O (2013) AqF026 is a pharmacologic agonist of the water channel aquaporin-1. J Am Soc Nephrol 24:1045-1052.

Yool AJ, Stamer WD, and Regan JW (1996) Forskolin stimulation of water and cation permeability in aquaporin 1 water channels. Science 273:1216-1218.

Address correspondence to: Andrea J. Yool, Adelaide Medical School, Helen Mayo South, Frome Road, University of Adelaide, Adelaide 5005 Australia. E-mail: andrea.yool@adelaide.edu.au 